\title{
The Electrical Properties of a 2D Conductive Zone under the Juan de Fuca Ridge
}

\author{
Marion Jegen and R.N. Edwards \\ Department of Physics, University of Toronto, Toronto, Canada
}

\begin{abstract}
Vertical gradient electromagnetic sounding (VGS) on the Endeavour segment of Juan de Fuca midocean ridge reveals the presence of a $2 \mathrm{D}$ ridge-parallel, conductivity anomaly. If the anomaly is caused mainly by melt in a conventional upper mantle upwelling zone alone, then the conductivity of the zone is about $0.6 \mathrm{~S} / \mathrm{m}$. The corresponding Archie's law melt fraction exceeds 0.10. A significantly lower melt fraction requires a sheet-like, well interconnected melt. Upwelling zone conductivity can be reduced by a third if the anomaly is broadened and a crustal conductor is added to the model.
\end{abstract}

\section{Introduction}

Forsyth [1991] and Turcotte and Morgan [1991] review the methods and results of numerical modeling of mantle upwelling and melt emplacement at the mid-ocean ridge. Models satisfying observed geophysical and petrophysical constraints fall into two broad categories. Sparks and Parmentier [1991] and Phipps Morgan et al [1987] propose a broad mantle upwelling region containing well-connected partial melt and melt migration focused towards the neovolcanic zone (melt migration model) while Buck and $S u$ [1989] and $S u$ and $B u c k$ [1991] suggest a narrow mantle upwelling zone with a mainly vertical melt migration pattern and a partial melt with a low degree of connectivity (dynamic model). Model discrimination requires additional geophysical data. Electrical conductivity is a parameter particularly sensitive to fluid content in a rock and, at mantle temperatures, the degree and connectivity of partial melt. The different upwelling models are evaluated by converting the petrology of the crust and the predicted upwelling region into their electrical analogs, and comparing the response of these analogs with experimental data from the Juan de Fuca ridge.

\section{Vertical Gradient Sounding}

Natural field electromagnetic vertical gradient sounding (VGS) was used successfully by Law and Greenhouse [1981] to map the seismic low-velocity zone beneath the Juan de Fuca plate. Temporal variations of the geomagnetic field caused by currents in the ionosphere and magnetosphere are recorded on the seafloor and at a nearby land reference station. If the electrical conductivity varies only with depth, then any horizontal component of the surface $B_{0}$ and the seafloor $B_{1}$ fields expressed as a function of angular frequency $\omega$ are related to the well-known magnetotelluric (MT) impedance $Q_{1}=\mu_{0} E_{1} / B_{1}$ on the seafloor as

Copyright 1998 by the American Geophysical Union.

Paper number 98GL52807.

0094-8534/98/98GL-52807\$05.00

$$
T(\omega)=\frac{B_{1}(\omega)}{B_{0}(\omega)}=\left[\frac{Z_{0} / \sinh \left(\phi_{0} h_{0}\right)}{Z_{0}+Q_{1} \tanh \left(\phi_{0} h_{0}\right)}\right],
$$

where $T$ is the VGS response parameter, $E_{1}$ is the seafloor electric field orthogonal to $B_{1}, \phi_{0}^{2}=i \omega \mu \sigma_{0}, Z_{0}^{2}=i \omega \mu / \sigma_{0}$, and $\sigma_{0}$ and $h_{0}$ are the conductivity and thickness of the sea respectively.

The impedance $Q_{1}$ may be found for an $N$-layered structure, layer parameters $h_{i}$ and $\sigma_{i}$, through the upward recursion rule

$$
Q_{i}=Z_{\imath}\left[\frac{Q_{i+1}+Z_{\imath} \tanh \left(\phi_{i} h_{i}\right)}{Q_{i+1} \tanh \left(\phi_{i} h_{i}\right)+Z_{\imath}}\right],
$$

where $\phi_{i}^{2}=i \omega \mu \sigma_{\imath}, Z_{i}^{2}=i \omega \mu / \sigma_{i}$ and $Q_{N}=Z_{N}$.

Given estimates the VGS parameter for a range of frequencies, expression (1) may be inverted using standard MT techniques to a layered earth model. If the earth structure is not $1 \mathrm{D}$, then interpretation proceeds by matching computed estimates of the magnetic field ratios from a specific model directly with the measured data. We use a numerical algorithm written by T.R. Madden. The rule (1) connecting $Q_{1}$ on the seafloor and $T$ is not valid in $2 \mathrm{D}$ or $3 \mathrm{D}$.

Jegen [1997] presents an analysis of the physics of the VGS method summarized here. For frequencies in the band in which ridge features are visible, $10^{-3}$ to $10^{-1} \mathrm{~Hz}$, significantly more current is induced by the external field in the ocean layer than in the subjacent crust. The proportion is just $1-|T|$ which has a value greater than 0.9 over these frequencies for typical earth models (see Fig. 1). The horizontal magnetic fields on the seafloor generated by the external currents and by the induced currents in the sea layer almost cancel each other. The residual field on the seafloor is caused by currents induced in the half-space and is diagnostic of crustal conductivity.

The seafloor magnetic field is related to integrated current flow. It is not distorted by local, small scale inhomogeneities. Further, the effect of large scale 2D topography typical of ridge environments is minimal. Current flow in the sea normal to the ridge is squeezed into a thinner sea layer but the process, in accordance with Ampere's law, does not effect the seafloor horizontal magnetic field significantly.

In a 2D study, Jegen [1997] examined the effect of a small cylindrical conductivity anomaly at depth added to a 1D model. The conductivity anomaly perturbs crustal current flow both along and across its strike, in the TE and TM modes respectively. For both polarizations, the anomalous horizontal magnetic field generated on the seafloor is twice the field of the anomalous current pattern. The advantageous, doubling effect may be represented by an image source above the seafloor representing the effect of induction by the anomaly in the seawater. 

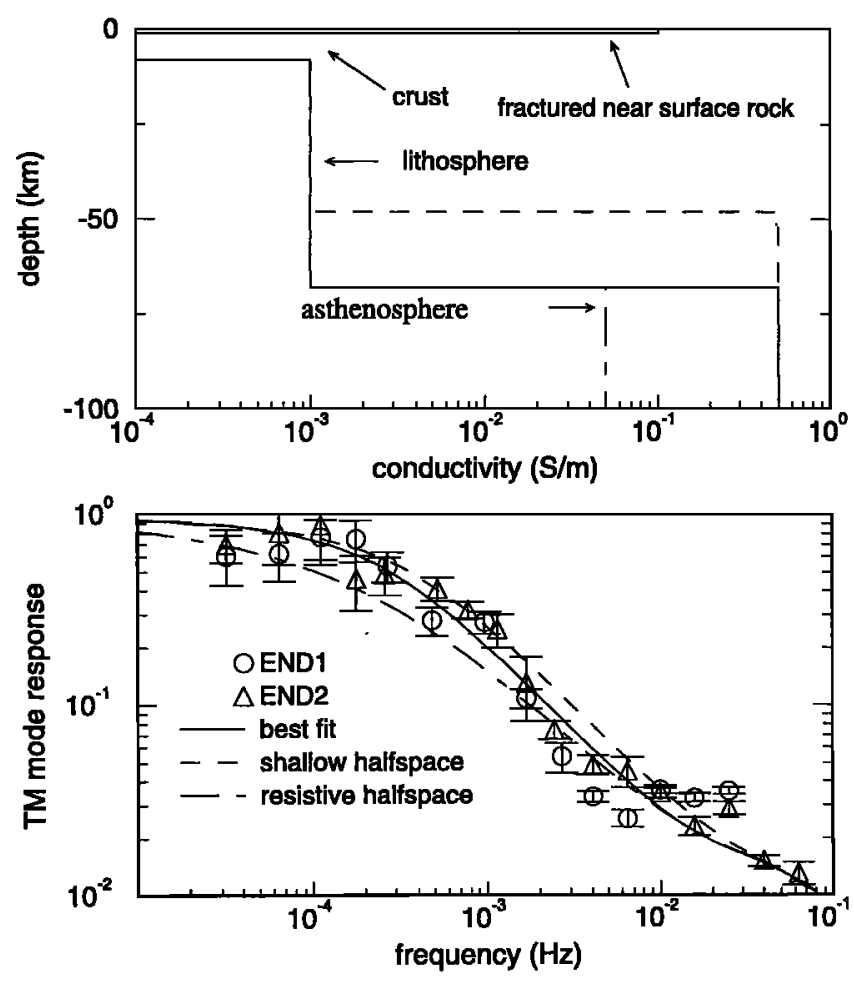

Figure 1. The $T M$ mode VGS response derived from measured data at END1 and END2 plotted as a function of frequency and compared with responses calculated for layered earth models shown above them

\section{Experiment}

The experimental data presented here were collected on the Endeavour segment of the Juan de Fuca ridge. Davis and Currie [1993] summarize geophysical observations there. Although the spreading rate is in the intermediate range at $58 \mathrm{~mm} / \mathrm{yr}$, a shallow mean axial depth of the ridge system and the high subsidence rate on the order of $350 \mathrm{~m} / \overline{M a}$ suggest that the mantle temperature is rather high [Klein and Langmuir,1987; Forsyth, 1991] and the melt supply is robust. The Endeavour segment is $90 \mathrm{~km}$ long. It has a well developed axial ridge. The axial high is $4 \mathrm{~km}$ wide at the shallowest depth of $2.2 \mathrm{~km}$ with an inner rift $1 \mathrm{~km}$ wide and $100 \mathrm{~m}$ deep. In its axial morphology, it is similar to fast spreading ridges, like the East Pacific Rise (EPR).

Seafloor magnetic records $60 \mathrm{hrs}$ long, sampled at $0.1 \mathrm{~Hz}$, and $55 \mathrm{hrs}$ long, sampled at $1 \mathrm{~Hz}$, were collected on two seafloor stations, END1 $\left(48^{\circ} 11.90^{\prime} \mathrm{N}, 129^{\circ} 24.04^{\prime} \mathrm{W}\right)$ and END2 ( $\left.47^{\circ} 56.02^{\prime} \mathrm{N}, 128^{\circ} 45.02^{\prime} \mathrm{W}\right)$ in 1992 and 1993 respectively using the highly-sensitive University of Toronto Ocean Bottom Magnetometer (OBM). The stations are at the center of the Endeavour segment, approximately $27 \mathrm{~km}$ and $16 \mathrm{~km}$ off the ridge axis at depths of 2680 and $2630 \mathrm{~m}$. Reference measurements were recorded at a landstation in Victoria, British Columbia for END1 and in Moclips, Washington for END2. The distance between the land and seafloor sites is about $350 \mathrm{~km}$, within the scale of uniformity of the surface horizontal field.

Data analysis involved the computation of VGS response $|T|$, the magnitude of the ratio of the seafloor and reference magnetic fields, as a function of frequency in two orthogonal directions, ridge normal (TE) and ridge parallel (TM) respectively. Jegen [1997] describes the processing techniques. Due to the low noise level of the OBM, $4 \mathrm{pT}$ per root hertz, the VGS response could be measured up to a frequency of $0.1 \mathrm{~Hz}$.

\section{Interpretation and Discussion}

The TM mode responses calculated for END1 and END2 are shown in Fig. 1. The data from different years at different sites with different reference stations overlap within the statistical error. Clearly, they cannot contain any obvious systematic error due to the reference station location. Further, they must be sensitive principally to regional structure as predicted by preliminary modeling studies.

Superimposed on the data are the responses of various regional layered models displayed in the upper panel of Fig. 1. The selected layered models differ in the conductivity and depth to a lower conductive half-space. The set of all models that fit the data require an integrated conductivity of no more than $100 \mathrm{~S}$ in the upper $20 \mathrm{~km}$, a condition we have satisfied through near surface high crustal conductivity, leaving the remainder of the zone resistive. All models require a conductive half-space at depth. The conductivity of the half-space is reflected in the value of the response at very low frequency; the depth to the half-space by the slope of the response. Our optimum model is compatible with the models derived in other MT experiments [Sinha et al., 1997; Oldenburg et al., 1984; Wannamaker et al., 1989] and with results of controlled-source seafloor EM experiments [Evans et al, 1991; Cox et al., 1986].

The TE mode responses are sensitive to both the 1D model and any $2 \mathrm{D}$ conductive structure beneath the ridge. Jegen [1997] searched extensively for an inverse parameter that best illustrated the nature of $2 \mathrm{D}$ features and settled on the parameter $J$, the difference in the magnitudes of the TE and TM mode responses divided by the magnitude of the TM mode response expressed in percent. Clearly, $J$ vanishes by definition over a $1 \mathrm{D}$ structure. Further, she showed that the 1D background model need be known only approximately for a reliable determination of the parameters of an embedded 2D anomaly to be made.

The measured $J$ response for the two sites is shown in Fig. 2 as a function of frequency. It differs noticeably from zero only in the frequency range $10^{-4}$ to $10^{-1} \mathrm{~Hz}$, peaking at about $5 \times 10^{-3} \mathrm{~Hz}$. The positive peak in the response reflects the presence of a relatively conductive anomaly. The anomaly is caused presumably by the presence of either partial melt in the mantle upwelling zone or crustal hydrothermal activity. The zone could be localized beneath the ridge as the response is smaller at END1 than at END2 which are located 27 and $16 \mathrm{~km}$ off-axis respectively.

We first matched the observed $J$ responses with computed responses for two structures representing the dynamic and melt-migration models (see upper panel, Fig. 2). The mantle upwelling zone in the melt migration model is represented by a broad conductive prism, 10 and $80 \mathrm{~km}$ wide at the top and base respectively. The same feature in the dynamic model is represented by a narrow sheet a constant $10 \mathrm{~km}$ in width. The background $1 \mathrm{D}$ model is our preferred layered model derived from the TM mode response alone.

The computed responses are shown as the curves through the data in Fig. 2 for a range of values of a constant con- 

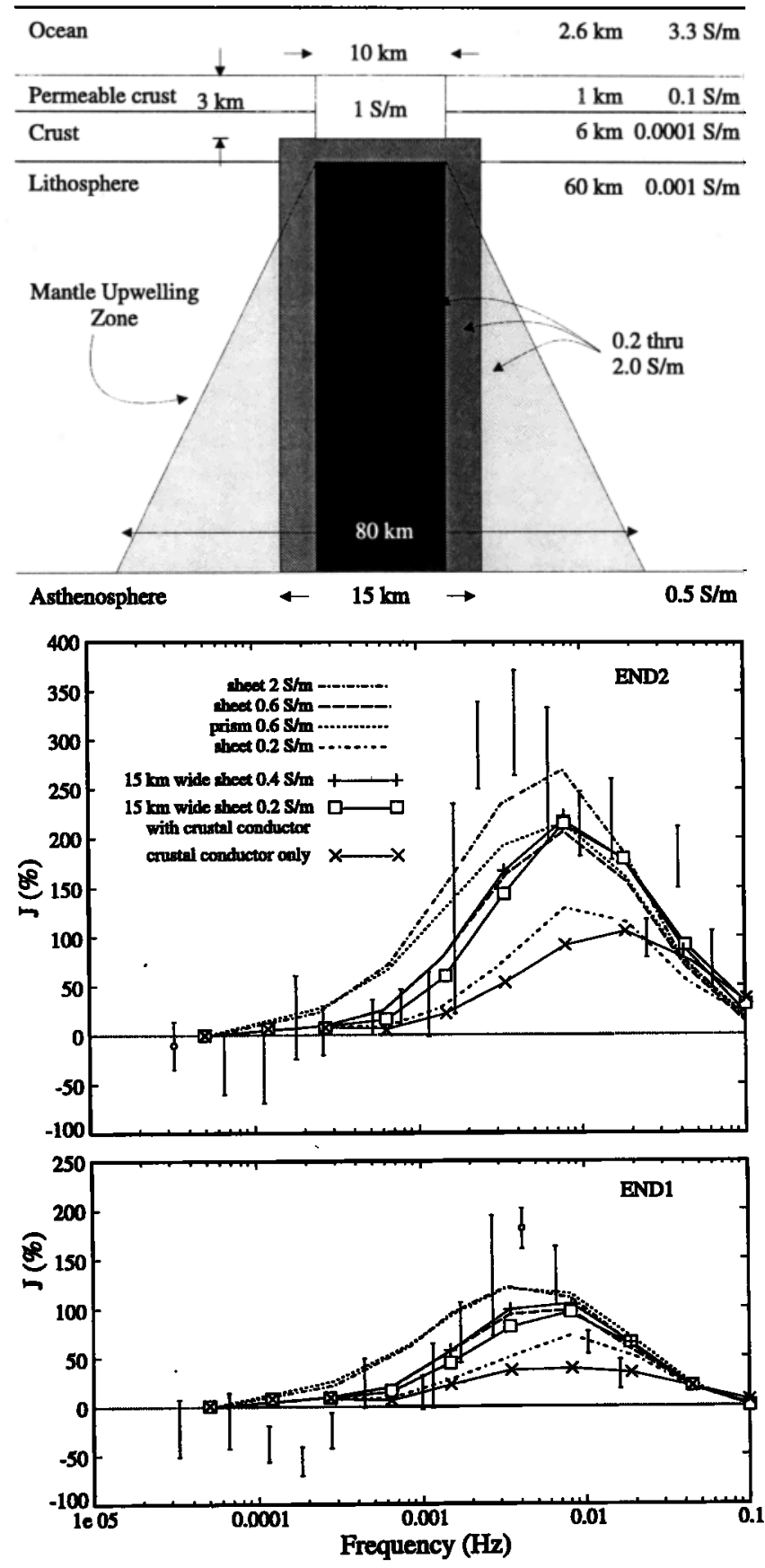

Figure 2. The two dimensional $J$ inverse parameter derived from measured data at END2 and END1 plotted as a function of frequency and compared with responses calculated for the models shown above.

ductivity within the upwelling zone. An increase in conductivity of the upwelling zone increases the amplitude of the $J$ response. It also broadens the frequency range of the response. For the sheet model, conductivities of 0.2 and $2 \mathrm{~S} / \mathrm{m}$ in the upwelling zone bracket the measured response while the optimum fit is at $0.6 \mathrm{~S} / \mathrm{m}$. The responses for the sheet model fit the observations marginally better than those for the equivalent prism model. A further marginal improvement in the chi-squared statistic can also be obtained by allowing the conductivity in sheet to be depth dependent.

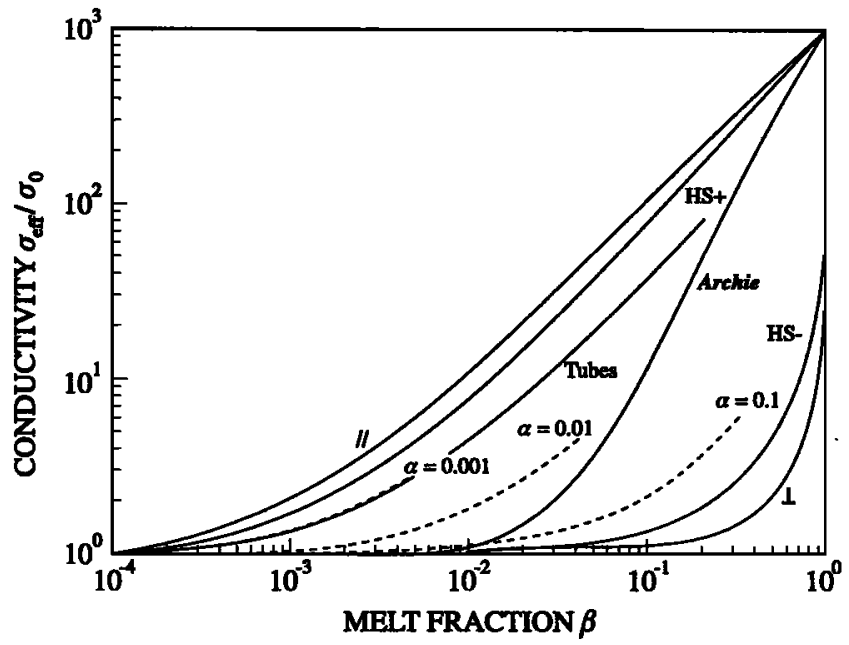

Figure 3. The derived conductivity $\sigma_{\text {eff }}$ of a mixture of partial melt and solid rock, conductivities $\sigma_{m}$ and $\sigma_{s}=$ $\sigma_{m} / 1000$ respectively, plotted against melt fraction for different mixing rules. The symbols $\perp$ and $\|$ represent models with thin fluid layers parallel and normal to the electric current flow, $\sigma_{+}$and $\sigma_{-}$, the upper and lower Hashin-Shtrikman bounds and $\alpha=0.001$ through 0.1 unconnected ellipsoidal inclusions of varying aspect ratios. Also shown are Archie's law and the effect of randomly oriented tubes.

The electrical conductivity of the two-phase material in the upwelling zone depends on the connectivity of the solid and fluid phase material, on the amount of partial melt present, and on the mechanical form of the mixture. Theoretical calculations of the effective conductivity $\sigma_{\text {eff }}$ of twophase materials of different forms have been conducted by Schmeling [1986]. His results are given in Fig. 3 for a contrast in conductivity between the melt $\sigma_{m}$ and the solid material $\sigma_{s}$ of 1000. Archie's law, an empirical relationship which reduces to $\sigma_{\text {eff }}=\sigma_{m} \beta^{2}$ for melt fraction $\beta$ above 0.05 , represents an average behaviour.

An estimate of the connectivity of melt requires a knowledge of a melt conductivity at temperatures and pressures typical of those beneath the ridge. The available data are limited. Tyburczy and Waff [1983] report measurements on Hawaiian theolitic melt under 15 kbar pressure in the range $1 \mathrm{~S} / \mathrm{m}$ to $10 \mathrm{~S} / \mathrm{m}$ for a corresponding temperature range of 1500 to $1700 \mathrm{~K}$. Since the derived anomaly conductivities are rather high we assume a melt conductivity of $10 \mathrm{~S} / \mathrm{m}$ in sample calculations to obtain minimum melt fractions for the various models. A commonly accepted maximum fraction is about 0.10 .

Assuming an intermediate connected melt described by Archie's law the estimated conductivity range, 0.2 to $2 \mathrm{~S} / \mathrm{m}$, would require a melt fraction exceeding 0.10 , in the range 0.14 to 0.44 . The range can be reduced to more reasonable values of 0.03 to 0.27 by assuming that the melt is completely interconnected - the upper Hashin-Shtrikman bound. As our data do not uniquely determine the distribution of conductivity beneath the ridge, we sought other geologically reasonable models consistent with the data that predict a lower partial melt fraction in the upwelling zone. The responses are also included in Fig. 2. If the upwelling zone is broadened to a uniform width of $15 \mathrm{~km}$, then the best estimate of 
the conductivity in the anomaly may be reduced by a factor of 1.5 from $0.6 \mathrm{~S} / \mathrm{m}$ to $0.4 \mathrm{~S} / \mathrm{m}$. Further, a model including a $1.0 \mathrm{~S} / \mathrm{m}$ conductive upper crustal anomaly $10 \mathrm{~km}$ wide and $3 \mathrm{~km}$ deep representing a hydrothermal zone, a $0.2 \mathrm{~S} / \mathrm{m}$ lower crustal anomaly $15 \mathrm{~km}$ wide to the base of the crust and a $15 \mathrm{~km}$ wide mantle anomaly reduced to $0.2 \mathrm{~S} / \mathrm{m}$ also fits the data. The corresponding melt fractions are 0.14 and 0.03 for the Archie and upper Hashin-Shtrikman bounds respectively. The response of the crustal conductivity anomaly alone is not large enough to fit the observed $J$ response. Increasing the conductivity above $1 \mathrm{~S} / \mathrm{m}$ would require average temperatures and porosities above $200^{\circ} C$ and 0.20 respectively assuming a pore fluid with the chemical composition of seawater.

Acknowledgments. We thank the captains and crews of the $R V$ Melville and the CFAV Endeavour. The research is supported by research and ship-time grants from the Natural Sciences and Engineering Research Council of Canada.

\section{References}

Buck, W.R. \& W. Su, Focused mantle upwelling below mid-ocean ridges due to feedback between viscosity and melting, Geophys. Res. Lett., 16, 641-644, 1989.

Cox, C.S., S.C. Constable, A.D. Chave \& S.C. Webb, Controlledsource electromagnetic sounding of the oceanic lithosphere, Nature, 320, 52-54, 1986.

Davis, E.E. \& R.G. Currie, Geophysical observations of the northern Juan de Fuca Ridge system: lessons in seafloor spreading, Can. J. Earth. Sci., 30, 278-300, 1993.

Evans, R.L., S.C. Constable, M.C. Sinha, C.S. Cox \& M.J. Unsworth, Upper crustal resistivity structure of the east pacific rise near $13^{\circ} \mathrm{N}$, Geophys. Res. Lett., 18, 1917-1929, 1991.

Forsyth, D.W., Geophysical constraints on mantle flow and melt generation beneath mid-ocean ridges, Geophysical Monograph, 71, 1-65, 1991.

Jegen, M.D., Electrical Properties of the Mantle Upwelling Zone beneath a mid-ocean ridge, an application of Vertical Gradient Sounding, Ph.D. thesis, University of Toronto, 1997.

Klein, E.M. \& C.H. Langmuir, Global correlations of ocean ridge basalt chemistry with axial depth and crustal thickness, $J$. Geophys. Res., 92, 8089-8115, 1987.
Law, L.K. \& J.P. Greenhouse, Geomagnetic variation sounding of the asthenosphere beneath the Juan de Fuca ridge, J. Geophys. Res., 86, 967-978, 1981.

Oldenburg, D.W., K.P. Whitall \& R.L. Parker, Inversion of ocean bottom magnetotelluric data revisited, J. Geophys. Res., 89, 1892-1833, 1984.

Phipps Morgan, J., E.M. Parmentier \& J.Lin, Mechanisms for the origin of mid-ocean ridge axial topography: Implications for the thermal and mechanical structure of accreting plate boundaries, J. Geophys. Res., 92, 12832-12836, 1987.

Schmeling, H., Numerical models on the influence of partial melt on elastic, anelastic and electrical properties of rocks. Part II: electrical conductivity., Phys. Earth Planet. Inter., 43, 123$126,1986$.

Sinha, M.C., D.A. Navin, L.M. MacGregor, S.C. Constable, C. Peirce, A. White, G. Heinson \& M.A. Inglis, Evidence for accumulated melt beneath the slow-spreading Mid-Atlantic Ridge, Phil. Trans. R. Soc. London, A355, 233-253, 1997.

Sparks, D.W. \& E.M. Parmentier, Melt extraction from the mantle beneath spreading centers, Earth Planet. Sci. Lett., 105, 368-377, 1991.

$\mathrm{Su}$, W. \& W.R. Buck, Factors causing melt concentration at midocean ridges, Eos Trans. AGU, 265, 1991.

Turcotte, D.L. \& J.P. Morgan, The physics of magma migration and mantle flow beneath a mid-ocean ridge, Geophysical Monograph, 71, 155-182, 1991.

Tyburczy, J.A. \& H.S. Waff, Electrical conductivity of molten basalt and andesite to 25 kilobars pressure: Geophysical significance and implications for charge transport and melt structure, J. Geophys. Res., 88, 2413-2430, 1983.

Wannamaker, P.E., J.R Booker, A.G. Jones, A.D. Chave, J.H. Filloux, H.S. Waff \& L.K. Law, Magnetotelluric observation across the Juan de Fuca subduction system in the EMSLAB project, J. Geophys. Res., 94, 14111-14125, 1989.

M. Jegen, Institute of Theoretical Geophysics, Department of Earth Sciences, University of Cambridge, Downing St., Cambridge CB2 2EQ, England (email: jegen@esc.cam.ac.uk)

R.N Edwards, Geophysics Division, Department of Physics, University of Toronto, Toronto, Ontario, M5S 1A7, Canada (email: edwards@geophy.physics.utoronto.ca)

(Received November 28, 1997; revised July 22, 1998; accepted August 14, 1998.) 